\title{
Towards a systemic approach to public safety
}

\author{
J. R. Santos-Reyes ${ }^{1}$, D. E. Santos-Reyes ${ }^{2}$ \\ \& L. M. Hernandez-Simon ${ }^{1}$ \\ ${ }^{1}$ Safety, Risk \& Reliability Research Group, \\ SEPI-ESIME, National Polytechnic Institute, Mexico \\ ${ }^{2}$ Industrial Engineering Section, Universidad de la Mixteca, Mexico
}

\begin{abstract}
Crime may be regarded as a major source of social concern in the modern world. Very often increases in crime rates will be treated as headline news, and many people see the 'law and order' issue as one of the most pressing in modern society. It may be argued that the existing approaches to managing crime prevention may not be good enough to deal with such events. In order to gain a full understanding and comprehensive awareness of crime risk in a given situation it is necessary to consider in a coherent way all the aspects that may produce it. In short there is a need for a systemic approach to public safety. Systemic means looking upon things as a system. A system may be defined as any entity, conceptual or physical, which consists of inter-dependent parts. To see things in a systemic way is to see events as the products of the working of a system. Given this, we may see 'crime' as the product of a system and, within that, see assault/robbery/sexual offence etc., as results of the working of systems. A systemic approach to crime prevention in Mexico City is being pursued. This paper gives an account of the work.
\end{abstract}

Keywords: crime risk, prevention, public safety, system, systemic.

\section{Introduction}

Crime may be regarded as a major source of social concern in the modern world. A significant proportion of daily newspapers' columns are devoted to reports on murder, theft and accounts of trials. Very often increases in crime rates will be treated as headline news, and many people see the 'law and order' issue as one of the most pressing in modern society. Crime and disorder may comprise a "vast set of events involving behaviour formally deemed against the law and usually 
committed with 'evil intent"' [1]. These events range from murder to fraud, theft, vandalism, dealing in drugs, kidnappings and terrorist atrocities that threaten the public safety. Public safety may be defined as "a state of existence in which people, individually and collectively, are sufficiently free from a range or real and perceived risks centering on crime and disorder, are sufficiently able to cope with those they nevertheless experience, and where unable to cope unaided, are sufficiently-well protected from the consequences of these risks" [1].

It may be argued that the existing approaches to managing crime prevention may not be enough to address the management of crime effectively. The soft systems methodology (SSM) has been adopted in order to investigate crime in Mexico City. It is hoped that it will prove itself more satisfactory for understanding the nature of crime.

\section{Public safety and its context}

\subsection{The nature of crime}

\subsubsection{Sexual and rape}

It is well documented that sexual assault and abuse have a profound effect on the victim's emotional functions, such as grief, fear, self-blame, emotional liability, including cognitive reactions such as flashbacks, intrusive thoughts, blocking of significant details of the assault and difficulties with concentration [2]. The offenders on the other hand display problems with empathy, perception about others, and management of negative emotions, interpersonal relationships, and world views [3]. On the other hand, rape is generally defined, in the literature, as a sexual act imposed to the victim by means of violence or threats of violence $[4,5]$. It is recognised that the most common motives for rape include power, opportunity, pervasive anger, sexual gratification, and vindictiveness. Also, it is emphasised that is important to understand the behavioural characteristics of rapists, and the attitudes towards rape victims.

\subsubsection{Murdering}

Very often murdering is a product of conflict between acquaintances or family members or a by-product of other type of crime such as burglary or robbery $[6,7]$. It is generally recognised that the role of cultural attitudes, reflected in and perpetuated by the mass media accounts, has a very significant influence in the public perception of crime.

\subsubsection{Organised crime}

The phenomenon of organised crime, such as smuggling or trafficking, is a kind of enterprise driven as a business: i.e., the pursuit of profits [8,9]. Smuggling or trafficking is usually understood as the organised trade of weapons or drugs, women and children, including refugees, but unlike the legal trade, smuggling or trafficking provides goods or services, based on market demand and the possibilities of realising it, that are illegal or socially unacceptable. Lampe and Johansen [10] attempt to develop a thorough understanding of organised crime, by clarifying and specifying the concept of thrust in organise crime networks. They propose four typologies that categorise trust as: (a) individualised trust, (b) 
trust based on reputation, (c) trust based on generalisations, and (d) abstract trust. They show that the existence of these types of trust through the examination of illegal markets.

\subsubsection{Battering}

Chiffriller et al. [11] discuss the phenomenon called battering, as well as batterer personality and behavioural characteristics. Based on cluster analysis, they developed five distinct profiles of men who batter women. And based on the behavioural and personality characteristics that define each cluster, they establish five categories: (1) pathological batterers, (2) sexually violent batterers, (3) generally violent batterers, (4) psychologically violent batterers, and (5) familyonly batterers. The authors discuss the implications for intervention of these categories.

\subsubsection{Bullying}

Burgess et al. [12] argue that bullying has become a major public health issue, because of its connection to violent and aggressive behaviours that result in serious injury to self and to others. The authors define bullying as a relationship problem in which power and aggression are inflicted on a vulnerable person to cause distress. They further emphasise that teasing and bullying can turn deadly.

\subsubsection{Terrorism}

Schmid $[13,14]$ defines terrorism as a form of violent conflicting-waging sometimes preceding, sometimes paralleling and sometimes substituting for other forms of conflict-waging. Conflict on the other hand is defined as an antagonistic situation or adversarial process between at least two individuals or collective actors over means or ends such as resources, power, status, goals, relations, or interests. This results traditionally in victory, defeat, domination, surrender, neutralisation, conversion, coercion, injury or destruction, and elimination of the opposite party or, alternatively, the solution settlement, or transformation of the conflict issue. Conflict occurs whenever individuals and groups of people have incompatible interests and goals and as such it is an unavoidable part of human interactions. Schmid further argues that the root causes of terrorism by non-state actors can rarely be understood without also looking at the behaviour of state-and-sponsored actors. The state can, both through its weaknesses (which provides opportunities for revolt) and through its strength (which might cause abuse of state power and bring about resistance from both civil and uncivil society) contribute to the emergence of terrorism.

Davis and Jenkins [15] propose three categories of principles aimed at analysing deterrence and influence terrorism; i.e., to increase the range of ways to counter al Qaeda activities. The first category emphasises no only on deterrence but also on influence. The second group of principles approaches terrorist organisations as complex systems, and the last category sets out the baseline for a persuasive strategy.

\subsubsection{Law enforcement}

Finckenauer [16] emphasizes that a major push of the expansion of higher education in crime and justice studies came particularly from the desire to 
professionalise the police - with the aim of improving police performance. He suggests new and expanded subject-matter coverage. First, criminal-justice educators must recognise that the face of crime has changed -it has become increasingly international in nature. Examples include cyber-crime, drug trafficking, human trafficking, other forms of trafficking and smuggling, and money laundering. Although global in nature, these sorts of crimes have significant state and local impact. The author argues that those impacts need to be recognised and understood by twenty-first-century criminal-justice professors and students. Increasingly, crime and criminals do not respect national borders. As a result, law enforcement and criminal justice cannot be bond and limited by national borders. Second, he emphasises the need to recognise that the role of science in law enforcement and the administration of justice has become increasingly pervasive and much more sophisticated. This role includes such as developments as DNA testing and evidence, the use of less-than-lethal weapons, increasingly sophisticated forms of identification, and crimes such as identity theft and a variety of frauds and scams. The use of scientific evidence and expert witnesses is also a significant issue in the prosecution and adjudication of offenders. Third, he puts emphasis on public security and terrorism. This has shaped, and will continue to shape, criminal justice in a variety of ways. Given the nature of terrorism and terrorists, the issues and subject matter related to them include the legal and constitutional questions surrounding the handling of terrorism suspects, racial and ethnic profiling, infrastructure security, the roots of terrorism, its domestic and international varieties, and the unique challenges presented to criminology and criminal justice by this phenomenon. Fourth, it is the need to recognise that the current move toward evidence-based criminaljustice policy requires the application of rational-empirical methods to improve crime control and prevention so as to effectively reduce the impact of crime on individuals, families, and communities.

Ratcliffe [17] emphasises on the practice of intelligence driven policing as a paradigm in modern law enforcement in various countries, such as UK, USA, Australia and New Zealand. The author proposes a conceptual model of intelligence driven policing that intends to overcome some difficulties of this new paradigm. This model essentially entails three stages: (1) law enforcement interpret the criminal environment, (2) influence decision-makers, and (3) decision-makers impact on the criminal environment.

It should be noted that most of the types of crime or other aspects related to crime mentioned above overlap and the order given is not meant to imply any kind of order of importance but it is simply a list of some types of crime which should be considered for analysis. Other types or factors related to crime may also be relevant.

\subsection{The surveys}

In 1989 the International Crime Victim Survey (ICVS) was born and since then it has contributed to the international knowledge of crime trends in different countries [18]. It is believed that since its conception standardized victimization surveys have been conducted in more than 70 countries worldwide. The ICVS 
has been surrounded by a growing interest by both the crime research community and the policy makers. A part of providing an internationally standardized indicators for the perception and fear of crime across different socioeconomic contexts; it also contributes to an alternative source of data on crime. Similarly, in Mexico, four National Crime Victim Surveys (they are known as ENSI-1,2,3\&4 respectively) have been conducted since 2001. The surveys are intended to help to provide a better knowledge of the levels of crime which affect the safety of the Mexican citizens [19]. Some key findings of the fourth (ENSI-4) are shown in Tables 1 and 2.

Table 1: $\quad$ Victimization [19].

\begin{tabular}{|l|c|}
\hline \multicolumn{1}{|c|}{ Types of crime } & Percentage (\%) \\
\hline$\{1\}$ robbery & 56.3 \\
$\{2\}$ other types of robbery & 25.8 \\
$\{3\}$ assault & 7.2 \\
$\{4\}$ theft of items from cars (e.g. accessories) & 2.9 \\
$\{5\}$ burglary & 2.4 \\
$\{6\}$ theft of car & 1.5 \\
$\{7\}$ other types of crime & 0.4 \\
$\{8\}$ kidnapping & 2.1 \\
$\{9\}$ sexual offences & 0.8 \\
$\{10\}$ other assault/threat to citizens & 0.6 \\
\hline
\end{tabular}

Table 2: $\quad$ People's perceptions of crime [19].

\begin{tabular}{|l|c|}
\hline \multicolumn{1}{|c|}{ Activities that citizens' have given up doing - } & Percentage (\%) \\
\hline$\{1\}$ going out at night & 49.1 \\
$\{2\}$ going to the football stadium & 17.1 \\
$\{3\}$ going to dinner out & 19.8 \\
$\{4\}$ going to the cinema or theater & 21.3 \\
$\{5\}$ carrying cash in their pockets & 45.4 \\
$\{6\}$ taking public transport & 28.1 \\
$\{7\}$ wearing jewelry & 56 \\
$\{8\}$ taking taxis & 37 \\
$\{9\}$ carrying credit cards & 38 \\
$\{10\}$ visiting friends or relatives & 30.5 \\
$\{11\}$ other & 1.6 \\
\hline
\end{tabular}

Overall, the public's perceptions of safety show that 9 out of 10 citizens feel unsafe in Mexico City. More than half of the population believes that crime has affected their quality of life; for example, Table 2 shows that one in two citizens gave up wearing jewelry, going out and taking cash in their pockets. 


\section{The need for a systemic approach}

\subsection{Systems thinking}

Systems thinking emerged in the last century through a critique of reductionism. Reductionism generates knowledge and understanding of phenomena by breaking them down into constituent parts and then studying these simple elements in terms of cause and effects [20-38]. As Ackoff [21] puts it:

"Reductionism...consists of the belief that everything in the world and every experience of it can be reduced, decomposed or disassembled down to ultimately simple elements, indivisible parts".

On the other hand, systems thinking argues that phenomena are understood to be an emergent property of an interrelated whole. Emergence and interrelatedness are some of the fundamental ideas of systemic thinking. An emergent property of a whole is said to arise where a phenomenon cannot be fully comprehended in terms only of properties of constituent parts; the interaction of the parts produces characteristics which are systemic; i.e. "The whole is greater than the sum of its parts"; and the whole is affected by the part and the part is affected by the whole.

In general, there is a whole literature discussing the meaning of 'system' and the advantages of systemic over reductionistic thinking [20-37]. However, the main purpose of this section is to introduce systems ideas in a way which is directly relevant to crime and this is dealt with in the next section.

\subsubsection{The need for a systemic approach}

In order to gain a full understanding and comprehensive awareness of crime risk in a given situation it is necessary to consider in a coherent way all the aspects that may produce it. In short, there is a need for a systemic approach to public safety. Systemic means looking upon things as a system. A system may be defined as any entity, conceptual or physical, which consists of inter-dependent parts. To see things in a systemic way is to see events as the products of the working of a system. Given this we may see 'crime' as the product of a system and, within that, see assault/robbery/sexual offence etc., as results of the working of systems.

\subsubsection{Approaches to systems}

One of the revelations that have wooed a large number of contemporary system thinkers is the fact that there are two paradigms; i.e., 'hard' and 'soft' [25-27,31-38]. These are based on contrasting assumptions that led to very different methodological principles. The 'hard' view regards problems as real and solvable and the primary concern of hard methodologies is how we should reach predefined ends, or "how should we do it" [31]. On the other hand, the 'soft' view believes that problem situations arise when people have contrasting views on the "same situation". The notion of a plurality of possible viewpoints and acceptance of many "relevant problems" emerges. The main focus of the 
'soft' approach is: "what should be done?" [31]. In the present research project the 'soft' view which is the paradigm inhabited by the Soft Systems Methodology (SSM) $[25,27]$ has been adopted to inquiry crime in Mexico City.

\subsection{The soft systems methodology (SSM)}

The SSM was developed by Checkland [25,27] and is shown in Fig. 1. In essence, it is an iterative process of inquiry with seven stages; i.e., stage 1: the problem situation unstructured; stage 2: rich pictures, issues \& primary tasks; stage 3: relevant systems and their root definitions; stage 4: conceptual models; stage 5: comparison of conceptual model with rich picture; stage 6: debate with people involved in the situation, and stage 7 : implementation of agreed changes. A brief account of each of the above stages will be described in the subsequent paragraphs.

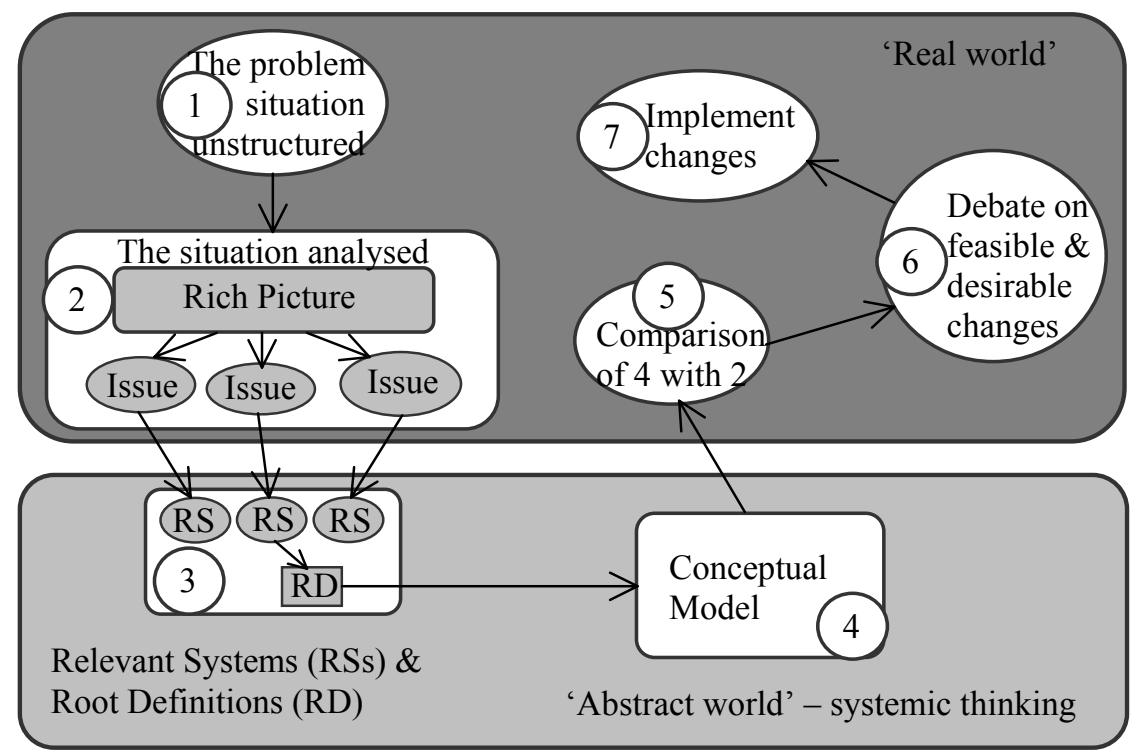

Figure 1: $\quad$ The soft systems methodology (SSM).

Stage 1: An inquiry begins, not with a 'problem' as such, but with a 'mess', or with an organizational setting in which someone thinks problems may reside. For example, 'We do not have the mechanisms to prevent crime'. The basic idea at this stage is that every problem exists in a context, and that context may be perceived differently by different people. The first task is to assemble a representation or picture of the situation which is rich in both quantitative or factual, and qualitative and subjective information. The analyst will try to portray the situation without imposing on a priori analytical framework upon it and in particular, the temptation to see the situation as a particular 'problem type' will be resisted. Having assembled a 'Rich Picture' of the situation (Stage 2), the 
analyst reflects upon it. It is emphasised that the analyst will not look for specific 'problems' for which particular 'solutions' can be proposed. Instead he seeks general patterns or issues which express characteristics of the situation. This leads to stage 3 and a search for systemic ways of viewing the situation; i.e., ways which are articulated by naming hypothetical systems, known in the methodology as 'Relevant Systems' (RSs).

The main objective of naming such systems is to find some potentially fruitful way of viewing the problem situation by thinking up some notional systems which might elucidate significant aspects of it. Different RSs may be based on different weltanschauungen (world-view); for example, if the problem situation is robbery, two possible RSs might be: "a system for making money", and "a citizens' fears induced system". The identification of RSs is a crucial stage in the inquiry, because it forces the analyst to choose to view the situation in a particular way. In the SSM there is nothing to prevent the analyst to take several different views, and working through the subsequent stages of the methodology with each.

The remaining stages; i.e., stages 4,5\&6 deal with the logical consequences of taking the particular view by the adopted RS. This is achieved by fleshing out the initial notion of the system: first, (stage 3 ) by describing it precisely by words (in the so called 'Root Definition') and second, (stage 4) by deriving an activity model called 'Conceptual Model' which contains all the essential activities which the notional system would logically have to perform. It should be noted that this conceptual model is a representation of an activity-system, i.e. a system whose elements are activities. In stage 5, the abstract model is then compared with what is perceived to exist in the actual problem situation.

In general, the comparison stage (i.e. stage 5) will throw up discrepancies between the real world situation and the abstract model of stage 4 . Two kinds of outcome are expected to be the outcome of this stage: $\{1\}$ a reassessment of the analyst's view of the problem setting, and some different ideas for RSs; $\{2\}$ an agenda of possible changes which, in stage 6 , is debated with the people who are involved in the problem situation. The main purpose of the debate is to identify changes which are feasible and desirable. Any change(s) which survive this process of scrutiny are then carried forward to the final stage for implementation (i.e. stage 7).

\section{Conclusions}

A systemic approach to inquiry crime in Mexico City has been put forward. This way at looking at crime is an alternative to earlier thinking and it is hoped that it will prove itself more satisfactory for understanding the nature of crime risk.

\section{Acknowledgements}

This project was funded by CONACYT \& SIP-IPN under the following grants: CONACYT-No. 52914 \& SIP-IPN-No. 20060219/20071593. 


\section{References}

[1] Ekblom, P. How to police the future: scanning for scientific and technological innovations which generate potential threats \& opportunities in crime, policing \& crime reduction (Chapter 2). Crime Science - new approaches to prevent \& detecting crime, ed. M.J. Smith \& N. Tilley, Willan Publishing, pp. 27-55, 2005.

[2] Alaggia, R., and Regehr, C. Perspectives of Justice for Victims of Sexual Violence, Victims and Offenders, 1, pp. 33-46, 2006.

[3] Alalehto, T. Eastern Prostitution from Russia to Sweden and Finland, Journal of Scandinavian Studies in Criminology and Crime Prevention, Vol. 3, pp. 96-111, 2002.

[4] Griffiths, H. Smoking Guns: European Cigarette Smuggling in the 1990's, Global Crime, vol. 6, No. 2, May, pp. 185-200, 2004.

[5] Puglia, M., Stough, C., Carter, J.D., and Joseph, M. The emotional intelligence of adult sex offenders: ability based EI assessment, Journal of Sexual Aggression, Vol. 11, No. 3, pp. 249-258, 2005.

[6] McCabe, M.P., and Wauchope, M. Behavioural characteristics of rapists, Journal of Sexual Aggression, Vol. 11, No. 3, pp. 235-247, 2005.

[7] Elklit, A. Attitudes toward Rape Victims - an Empirical Study of the Attitudes of Danish Website Visitors, Journal of Scandinavian Studies in Criminology and Crime Prevention, Vol. 3, pp. 73-83, 2002.

[8] Tucker, J. How not to Explain Murder: A Sociological Critique of Bowling for Columbine, Global Crime, Vol. 6, No. 2, May, pp. 241-249, 2004.

[9] Klein, J. Teaching her a lesson: Media misses boys' rage relating to girls in school shootings, Crime Media Culture, Vol. 1(1), pp. 90-97, 2005.

[10] Lampe, K.v., and Johansen, P.O. Organized Crime and Trust: On the conceptualization and empirical relevance of trust in the context of criminal networks, Global Crime, Vol. 6, No. 2, May, pp. 159-184, 2004.

[11] Chiffriller, S.H., Hennessy, J.J, and Zappone, M. Understanding a New Typology of Batterers: Implications for Treatment, Victims and Offenders, 1, pp. 79-97, 2006.

[12] Burgess, A.W., Garbarino, C., and Carlson, M.I. Pathological Teasing and Bulling turned Deadly: Shooters and Suicide, Victims and Offenders, 1, pp. 1-14, 2006.

[13] Schmid, A. Terrorism as Psychological Warfare, Democracy and Security, 1, pp. 137-146, 2005.

[14] Schmid, A.P. Root Causes of Terrorism: Some conceptual Notes, a Set of Indicators, and a Model, Democracy and Security, 1, pp. 127-136, 2005.

[15] Davis, P.K., and Jenkins, B.M. A Systems Approach to Deterring and Influencing Terrorists, Conflict Management and Peace Science, 21, pp. 3-15, 2004.

[16] Finckenauer, J.O. The Quest for Quality in Criminal Justice Education, Justice Quarterly, Volume 22, Number 4, December, pp. 413-426, 2005. 
[17] Ratcliffe, J. The effectiveness of Police Intelligence Management: A New Zealand Case Study, Police Practice \& Research, Vol. 6, No. 5, pp. 435451, 2005.

[18] Instituto Ciudadano de Estudios Sobre la Inseguridad (ICESI), online www.icesi.org.mx.

[19] The international Crime Victim Survey (ICVS). Online http://www.unicri.it/wwd/analysis/icvs/index.php.

[20] Emery, F.E. (ed.) Systems Thinking (2 vols). Harmondsworth: penguin. 1981.

[21] Ackoff, R. L. The systems revolution. Long Range Planning, 7(6), 2, 1974.

[22] Ackoff, R. L. Redesigning the future. New York: Wiley, 1974.

[23] Beer, S. Heart of enterprise. Chichester: Wiley, 1979.

[24] Bertalanffy, L. von. A systems view of man: collected essays. Violette, P.A. (ed.) Boulder, CO: Westview Press, 1981.

[25] Checkland, P. B. Systems thinking, systems practice. Chichester: Wiley, 1981.

[26] Checkland, P. B. and Holwell, S. Information systems, and information systems. Chichester: Wiley, 1998.

[27] Checkland, P. B. and Scholes, J. Soft systems methodology in action. Chichester: Wiley, 1990.

[28] Senge, P. M. The Fifth discipline, New York: Doubleday, 1990.

[29] Forrester, J. W. World dynamics. Cambridge, MA: MIT Press, 1971.

[30] Jackson, M.C. Systems methodology for the management science. New York: Plenum, 1991.

[31] Flood, R.L. and Jackson, M.C. Creative problem solving - total systems intervention, Chichester: John Wiley \& Sons, 1991.

[32] Flood, R. L. and Romm, N.R.A. (eds.) Critical systems thinking: current research and practice. New York: Plenum, 1996.

[33] Flood, R.L. Rethinking the Fifth discipline: learning within the unknowable. London: Routledge.

[34] Beard, A. N. Some ideas on a systemic approach. Civil Eng. And Env. Syst., Vol. 16, pp. 197-209, 1999.

[35] Fortune, J., and Peters, G. Learning from failures - the systems approach. Chichester: Wiley, 1995.

[36] Wolstenholme, E.F. System inquiry: a systemic dynamics approach. Chichester: Wiley, 1990.

[37] Santos-Reyes, J., and Beard, A.N. A systemic approach to fire safety management, Fire Safety Journal, 36, pp. 359-390, 2001.

[38] Santos-Reyes, J., and Beard, A.N. A systemic approach to tunnel fire safety management (Chapter 18), The Handbook of tunnel fire safety, ed. A.N. Beard \& R.A. Carvel, Thomas Telford, London, pp. 388-407, 2005. 